\title{
Effects of Optogenetic Activation of Corticothalamic Terminals in the Motor Thalamus of Awake Monkeys
}

\author{
(D)Adriana Galvan, ${ }^{1,2}$ Xing Hu (胡幸), ${ }^{1}$ Yoland Smith, ${ }^{1,2}$ and Thomas Wichmann ${ }^{1,2}$ \\ ${ }^{1}$ Yerkes National Primate Research Center and ${ }^{2}$ School of Medicine, Department of Neurology, Emory University, Atlanta, Georgia 30329
}

The role of the corticothalamic projection in the ventral motor thalamus remains poorly understood. Therefore, we studied the electrophysiological responses of neurons in the basal ganglia and cerebellar receiving-territories of the motor thalamus (BGMT and CbMT, respectively) using optogenetic activation of corticothalamic projections in awake rhesus macaques. After injections of viral vectors carrying the excitatory opsins ChR2 or C1V1 into the primary motor and premotor cortices of two monkeys, we used optrodes to light activate opsin-expressing neurons in cortex or their terminals in the thalamus while simultaneously recording the extracellular activity of neurons in the vicinity of the stimulation sites. As expected, light activation of opsins in the cerebral cortex evoked robust, short-latency increases in firing of cortical neurons. In contrast, light stimulation of corticothalamic terminals induced small-amplitude, long-latency increases and/or decreases of activity in thalamic neurons. In postmortem material, opsins were found to be expressed in cell bodies and dendrites of cortical neurons and along their corticothalamic projections. At the electron microscopic level, opsin labeling was confined to unmyelinated preterminal axons and small terminals that formed asymmetric synapses with dendrites of projection neurons or GABAergic interneurons in BGMT and CbMT and with neurons in the reticular thalamic nucleus. The morphological features of the transfected terminals, along with the long latency and complex physiological responses of thalamic neurons to their activation, suggest a modulatory role of corticothalamic afferents upon the primate ventral motor thalamus.

Key words: C1V1; ChR2; motor cortex; motor thalamus; optogenetics; single unit recording

\section{Significance Statement}

This study provides the first analysis of the physiological effects of cortical inputs on the activity of neurons in the primate ventral motor thalamus using light activation of opsin-containing corticothalamic terminals in awake monkeys. We found that selective light activation of corticothalamic terminals in contact with distal dendrites of thalamocortical neurons and GABAergic interneurons elicits complex patterns of slowly developing excitatory and inhibitory effects in thalamic neurons of the basal ganglia- and cerebellar-receiving regions of the motor thalamus. Our observations suggest a modulatory (instead of a "driver") role of the corticothalamic system in the primate ventral motor thalamus.

\section{Introduction}

Based on the observation that the ventral motor thalamus contains neurons with activity that is strongly modulated by movement (Strick, 1976; Anderson and Turner, 1991; Nambu et al., 1991; Butler et al., 1998; Kurata, 2005) and the finding of deficits

Received Dec. 4, 2015; revised Jan. 26, 2016; accepted Feb. 2, 2016.

Author contributions: A.G., Y.S., and T.W. designed research; A.G. and X.H. performed research; A.G. and X.H. analyzed data; A.G., Y.S., and T.W. wrote the paper.

The authors declare no competing financial interests.

This work was supported by the National Institutes of Health (NIH)/Office of Research Infrastructure Programs (Grant P51-0D011132 to the Yerkes National Primate Research Center), NIH/National Institute of Neurological Disorders and Stroke (NINDS Udall Center Grant P50-NS071669 and Grant GR01-NS083386 to T.W.). We thank Jean-Francois Pare, Damien Pittard, Yuxian Ma, and Susan Jenkins for expert technical assistance and Karl Deisseroth for the ChR2 and C1V1 DNA plasmids.

Correspondence should be addressed to Adriana Galvan, PhD, Yerkes National Primate Research Center, Emory University, 954 Gatewood Road, NE, Atlanta, GA 30329. E-mail: agalvan@emory.edu.

DOI:10.1523/JNEUROSCI.4363-15.2016

Copyright $\odot 2016$ the authors $\quad 0270-6474 / 16 / 363519-12 \$ 15.00 / 0$ in motor control or motor learning induced by lesions of this area (Canavan et al., 1989; Inase et al., 1996; van Donkelaar et al., 2000; Carrera and Bogousslavsky, 2006), the motor thalamus is thought to play an important role in the integration of movement-related information (Bosch-Bouju et al., 2013). The motor thalamus receives afferents from layers $\mathrm{V}$ and VI of the primary motor cortex (M1), supplementary motor area, and premotor cortex (PM) (Rouiller et al., 1998; Rouiller and Welker, 2000; McFarland and Haber, 2002). The layer V inputs are collaterals of corticobulbar and corticospinal axons that do not innervate the reticular thalamic nucleus (RT). In contrast, layer VI afferents provide axon collaterals to the RT as they enter the motor thalamus (Deschênes et al., 1994; Rouiller and Welker, 2000; Kakei et al., 2001). In primates, corticothalamic terminals contact thalamocortical neurons and GABAergic interneurons (which are absent from the rodent motor thalamus; Smith et al., 1987; Ilinsky and Kultas-Ilinsky, 1990; Jones, 2007). In addition 
to cortical and RT inputs (Pinault, 2004), the motor thalamus receives massive GABAergic afferents from the internal segment of the globus pallidus (GPi) and the substantia nigra reticulata $(\mathrm{SNr})$, as well as glutamatergic inputs from the deep cerebellar nuclei. In primates, $\mathrm{GPi} / \mathrm{SNr}$ and cerebellar afferents are largely segregated in different subnuclei of the ventral motor nuclear group (Ilinsky and Kultas-Ilinsky, 1987; Ilinsky, 1990; Percheron et al., 1996; but see Sakai et al., 1996; Sakai et al., 2000).

Based on studies of the sensory thalamus, the excitatory connections that govern thalamic function have been divided into "driver" inputs that carry peripheral (or cortical) information to the thalamus and "modulatory" inputs that originate from layer VI corticothalamic neurons (for review, see Sherman, 2012). These populations of terminals are structurally and functionally different. Although the driver terminals are large and form multiple synapses with the distal and proximal parts of their synaptic targets, the modulatory terminals are generally small and target almost exclusively distal dendrites (Kultas-Ilinsky and Ilinsky, 1991; Miyata, 2007; Sherman and Guillery, 2011; Rovó et al., 2012). In high-order sensory nuclei such as the pulvinar, the driver afferents originate from layer $\mathrm{V}$ cortical neurons and have morphological and functional characteristics that are comparable to those of drivers from subcortical sources in first-order nuclei (Sherman, 2005; Rovó et al., 2012). However, cortical boutons do not display the features of driver-like terminals in the motor thalamus (Rovó et al., 2012). Although cerebellar terminals act as drivers in the cerebellar-receiving territory of this thalamic region, the basal ganglia-receiving thalamic nuclei are devoid of large, "driver-like" glutamatergic terminals (Bodor et al., 2008; Kuramoto et al., 2011; Rovó et al., 2012). Instead, they contain multisynaptic GABAergic terminals from the GPi/SNr that provide a strong inhibitory control of thalamocortical neurons (Ilinsky and Kultas-Ilinsky, 1990; Ilinsky et al., 1997; Sidibé et al., 1997; Bodor et al., 2008; Rovó et al., 2012).

In light of the differences in the cellular and synaptic organization of the motor thalamic nuclei compared with other thalamic regions and the abundance of GABAergic interneurons in the primate thalamus, the description of the cortical modulation of thalamic relay neurons in the rodent sensory thalamus does not necessarily apply to the corticothalamic interaction in the primate motor thalamus. In this study, we therefore characterized the physiological effects of activating cortical afferents upon neurons in the basal ganglia- and cerebellar-receiving motor thalamus in awake monkeys using an optogenetic approach that allowed us to stimulate corticothalamic inputs selectively. Our results show significant heterogeneity in the responses of thalamic neurons to the optical activation of their cortical inputs with frequent inhibition of activity, likely indicating engagement of intrathalamic GABAergic circuits.

\section{Materials and Methods}

\section{Animals and surgical preparation}

These studies were performed following the Guide for the Care and Use of Laboratory Animals (Garber et al., 2011) and the U.S. Public Health Service Policy on the Humane Care and Use of Laboratory Animals (revised 2015). The studies were approved by the Animal Care and Use Committee and the Biosafety Committee of Emory University.

We used two male rhesus monkeys (Macaca mulatta), aged 2.2 (monkey W) and 2.9 (monkey V) years at the beginning of the studies. The monkeys were obtained from the colony at the Yerkes National Primate Research Center, were housed in pairs with other monkeys, had ad libitum access to food and water, and received vegetables and fruits daily. The monkeys were trained to sit on a primate chair using the pole and collar method along with positive reinforcements (McMillan et al., 2014).

We prepared the animals for the chronic electrophysiology experiments during a surgical procedure performed under anesthesia (1-3\% isoflurane) and using aseptic techniques. Two recording chambers (19 $\mathrm{mm}$ internal diameter; Crist Instrument) were positioned on the skull in the coronal plane with a $50^{\circ}$ angle from the vertical. The chambers were directed stereotaxically to cortical areas M1 and PM (area 4 and dorsocaudal and ventrocaudal portions of area 6 according to Paxinos et al., 2000) and to the basal-ganglia- and cerebellar-receiving motor thalamus (BGMT and CbMT, respectively). These areas correspond to ventral anterior lateral, medial ventral lateral, and lateral ventrolateral thalamus according to the Paxinos atlas (Paxinos et al., 2000). We also implanted a head bolt for head fixation and used metal screws and dental acrylic to attach the hardware to the skull. The recording chambers were cleaned routinely with sterile saline (at least three times per week) for the duration of the studies.

\section{Electrophysiological recordings}

During all electrophysiological recording sessions, the monkeys sat on a primate chair with their heads restrained and were continuously monitored with live video. They remained awake throughout the session, as judged by eye opening and body movements. To lower microelectrodes (tungsten electrodes, $Z=0.5-1.0 \mathrm{M} \Omega$ at $1 \mathrm{kHz}$; FHC) into the brain, we used a microdrive (NAN Instruments) and a 21 -gauge guide cannula.

Extracellular neuronal signals were amplified (DAM-80 amplifier; WPI) and filtered (400-6000 Hz; Krohn-Hite). The signals were monitored with an oscilloscope (DL1540; Yokogawa) and speakers connected to an audio amplifier and sampled at $25 \mathrm{ks} / \mathrm{s}$ to computer disk (Power1401 and Spike2 software; CED).

The target brain structures were identified with electrophysiological mapping according to their stereotaxic location, their depth in the dorsoventral plane, and their relationship with other structures. The location of M1 was further defined by its responsiveness to microstimulation (30-50 $\mu \mathrm{A}, 30$ pulses, $30-200 \mathrm{~Hz}$, biphasic stimulation, $300 \mu \mathrm{s} /$ phase; Turner and DeLong, 2000). The current was delivered through the tungsten recording microelectrode. The stimulation was timed by a computer through the Power 1401 interface and generated with a constant current stimulus isolator (395R; WPI). The presence of body movements in response to the microstimulation was assessed visually by two examiners.

The borders of the motor thalamus were defined using the electrophysiologic signatures of neighboring structures, including the putamen, the external and internal segments of the globus pallidus, the internal capsule, the caudate nucleus, and the subthalamic nucleus (DeLong, 1971, 1973; Wichmann et al., 1994). We attempted to use passive somatosensory examination to identify BGMT and CbMT thalamic neurons (Vitek et al., 1994), but this was not consistently possible due to excessive movements of the monkeys during the examination. The distinction between the CbMT and the BGMT was therefore based on postmortem anatomical reconstructions of the electrode tracks.

\section{Injections of adeno-associated viral vectors}

We used adeno-associated viral vectors $2 / 5$ (a hybrid of serotypes 2 and 5) containing the genetic sequence for hChR2(H134R) or C1V1(E122T/ E162T) both under the control of the CaMKII $\alpha$ promoter and fused to the gene for enhanced yellow fluorescent protein (EYFP). The DNA plasmids were provided by Dr. Karl Deisseroth (Stanford University, Stanford, CA) and the vectors $\left(3-4 \times 10^{12} \mathrm{vg} / \mathrm{ml}\right.$ ) were prepared by the Gene Therapy Center at the University of North Carolina (Chapel Hill, NC).

Once the electrophysiological mapping was complete, we injected the AAV solution in M1 and PM under electrophysiologic guidance using a probe in which the injection tubing was combined with a recording microelectrode (Kliem and Wichmann, 2004). We conducted extracellular recordings while lowering the injection system to help us to define the final location of the injections in the deep cortical layers (layers $\mathrm{V}$ and VI). A total of 8-11 injection tracks were done in each hemisphere and 2-5 $\mu$ l of virus solution was injected per track.

Because optogenetic stimulation of corticothalamic terminals has not been reported previously in primates and because ChR2 and C1V1 differ 
in their light sensitivity, peak wavelength activation, and dynamics (Mattis et al., 2012), we tested both excitatory opsins (each animal received one of the two opsins in opposite hemispheres).

\section{Data collection}

After the virus injections, we waited at least 5 weeks before starting the light stimulation experiments. To stimulate the opsins, we used optical fibers [BFH37-200, 0.37 numerical aperture (NA), or FT200UMT, 0.39 NA; Thorlabs] that were glued to a tungsten microelectrode (same type as used for electrophysiological mapping). These "optrodes" were assembled with the tip of the fiber positioned $\sim 0.3 \mathrm{~mm}$ above the recording end of the electrode, as described previously (Galvan et al., 2012). The fibers were connected to either a blue $(473 \mathrm{~nm}, 25 \mathrm{~mW}$, Crystalaser, or $473 \mathrm{~nm}, 100 \mathrm{~mW}$, Shanghai Laser and Optics Century) or a green laser (532 nm, $100 \mathrm{~mW}$; Shanghai Laser and Optics Century) to activate ChR2 or $\mathrm{C} 1 \mathrm{~V} 1$, respectively.

Optrodes were lowered in the brain with the microdrive using positions that were within $4.5 \mathrm{~mm}$ of the injection tracks for optical stimulation in M1 and PM or at predetermined coordinates in the BGMT and CbMT (as previously defined during the electrophysiological mapping). All optrode penetrations were separated by at least $1 \mathrm{~mm}$ in the mediolateral and anteroposterior directions. Once the optrode was placed in the area of interest, we tested the responses to light for every single neuron isolated with a signal-to-noise ratio of $>2: 1$. Opsins were activated with short trains of light pulses (10 pulses/train, $20 \mathrm{~ms} /$ pulse, $10 \mathrm{~Hz}$ ) and/or a series of long, single pulses (500 ms/pulse). At each testing site, at least 30 pulses or trains of pulses were delivered, spaced by $2-5 \mathrm{~s}$ (randomly chosen). The light intensity at the fiber output was measured (PM100 USB meter and S120C sensor; Thorlabs) and adjusted to 400$600 \mathrm{~mW} / \mathrm{mm}^{2}$ in most cases, although some neurons were tested with a range of $60-820 \mathrm{~mW} / \mathrm{mm}^{2}$.

To determine whether the optical stimulation in M1 induced motor responses (similar to those evoked with electrical microstimulation), we video-recorded the animal's movements while the light stimulation was being delivered. Each laser pulse was signaled by an LED positioned to be captured by the video camera but out of the monkey's visual field. The video footage was further analyzed offline.

\section{Data analysis}

The recorded spike trains were sorted offline, using waveform template matching, followed by principal component analysis and analysis of interspike interval (ISI) distribution histograms (Spike2). Data were accepted as originating from a single neuron if $<1 \%$ of ISIs were shorter than $2 \mathrm{~ms}$. In extracellular recordings, electrophysiological features such as the spike duration and shape do not seem to be sufficient to classify single cortical or thalamic units into projection neurons and interneurons (Vigneswaran et al., 2011). Therefore, we did not attempt to identify neuronal types in the cortex or thalamus. However, because the projection neurons are substantially larger than interneurons in either region (Deschênes et al., 1979; Ilinsky and Kultas-Ilinsky, 1990; Kultas-Ilinsky and Ilinsky, 1991), most of the recorded neurons were likely projection cells. Neurons with a spontaneous firing rate $>90$ spikes/s (10 neurons total) were excluded from the analysis.

To evaluate the electrophysiological responses to light stimulation, we constructed peristimulation time histograms (PSTHs) aligned to the start of stimulation trains or single light pulses. Trains of light pulses were analyzed in a PSTH of $3 \mathrm{~s}$, including a $1 \mathrm{~s}$ prestimulation control period, and binned in $25 \mathrm{~ms}$ intervals. To analyze the responses to the single 500 $\mathrm{ms}$ light pulses, we constructed $1.5 \mathrm{~s}-\mathrm{PSTH}$ with a prestimulation period of $500 \mathrm{~ms}$ and a bin size of $5 \mathrm{~ms}$.

We defined a significant response to the light stimulation on the basis of the corresponding PSTH as either an increase or a decrease in firing that lasted for at least 2 consecutive bins above or below 2 SDs from the neuron's average firing rate during the prestimulation period $(p=$ $0.001)$. In the few cases where the light stimulation produced combinations of increases and decreases in firing, only the earlier effect was considered. Some neurons had a very low firing rate in the prestimulation period of the PSTH, which resulted in a negative number when 2 SDs were subtracted from the mean. In these cases, an inhibitory response was defined as a segment without spikes lasting at least 2 bins longer than the longest silent segment during the prestimulation period.

As additional confirmation that the observed changes in firing during the opsin activation were due to the light stimulation, we constructed sham PSTHs using the same spike-timing data used for the actual PSTH but aligning the spikes to randomly spaced events. The sham PSTHs were analyzed as described above.

Most thalamic neurons did not respond to the light stimulation using trains of short pulses (see Results); therefore, we analyzed mostly the recordings made during the light stimulation with $500 \mathrm{~ms}$ pulses. The magnitude of the effect of light stimulation was calculated by normalizing the mean firing rate during the presence of the $500 \mathrm{~ms}$ light pulse by the mean firing rate during the control period (500 ms preceding the pulse). The latency to a significant change in firing rate was defined in PSTHs binned in $5 \mathrm{~ms}$. The first bin above or below 2 SDs was considered the start of the effect. The results obtained in ChR2- and C1V1transfected regions were compared statistically (Mann-Whitney tests) and pooled together when not significantly different; otherwise, they are reported separately. Statistical analysis was done using SPSS software (version 22; IBM). Data are expressed as means \pm SD.

\section{Histological procedures}

At the end of the light stimulation and electrophysiology experiments, the animals were killed with an overdose of pentobarbital $(100 \mathrm{mg} / \mathrm{kg}$, i.v.), and transcardially perfused with Ringer's solution and $4 \%$ paraformaldehyde and $0.1 \%$ glutaraldehyde in phosphate buffer $(\mathrm{PB}, 0.2 \mathrm{M}, \mathrm{pH}$ 7.4). We obtained coronal sections of the brain $(60 \mu \mathrm{m})$ with a vibratome (in cold PBS, $0.01 \mathrm{M}, \mathrm{pH} 7.4$ ). All histological procedures were done as described previously (Galvan et al., 2004, 2010, 2012, 2014).

Light microscopy immunoperoxidase. We used antibodies against GFP (which also detect the EYFP fused to ChR2 or C1V1, so we hereafter refer to these as EYFP antibodies) to examine the opsin expression. We selected brain sections ( 1 of every 6 sections) to encompass most of the motor cortices and motor thalamic regions (corresponding $\sim$ to $25-6$ $\mathrm{mm}$ anterior to the interaural line according to Paxinos et al., 2000). Sections were pretreated ( $10 \%$ normal goat serum, $1 \%$ bovine serum albumin, and $0.3 \%$ Triton X-100) and then incubated in EYFP antibody solution (raised in rabbit, 1:5000, catalog \#A-11122; Invitrogen) for $24 \mathrm{~h}$. Additional sections at the level of the thalamus were incubated with antibodies against vGluT2 (raised in rabbit, 1:5000, catalog \#VGT2-6; MAB Technologies) to help delineate the cerebellar-receiving area of the ventral motor nuclear group (Bodor et al., 2008; Kuramoto et al., 2011; Rovó et al., 2012). Exposure to primary antibodies was followed by incubation in the respective biotinylated antibodies (1:200; Vector Laboratories) and in $\mathrm{ABC}$ solution (1:200; Vectastain standard kit; Vector Laboratories) for $90 \mathrm{~min}$. Thereafter, the sections were placed in $0.025 \%$ 3-3'-diaminobenzidine tetrahydrochloride (DAB; Sigma-Aldrich), 0.01 M Imidazole (Fisher Scientific), and $0.006 \% \mathrm{H}_{2} \mathrm{O}_{2}$ for $10 \mathrm{~min}$. The sections were mounted on slides, covered, and digitized with an Aperio Scanscope CS system. Control sections were processed in solutions from which the primary antibodies were omitted.

To delineate the limits of M1, PM, BGMT, and CbMT, the scanned images were digitally overlaid using CorelDraw X5 (Corel) to outline drawings from the rhesus monkey brain atlas (Paxinos et al., 2000). The identification of thalamic nuclei was further assessed using the vGluT2stained sections. Areas rich in vGluT2 were considered to be part of CbMT (Bodor et al., 2008; Kuramoto et al., 2011; Rovó et al., 2012). To define the location of the recorded neurons, we used the tracks left by the recording probes. These tracks were visible in EYFP- and Nissl-stained sections.

To estimate the extent of the brain regions expressing the opsins, we used a series of EYFP-stained sections (360 $\mu \mathrm{m}$ apart) that encompassed the transfected cortical and thalamic regions. In digital images $(0.5 \times)$, we delineated EYFP-positive regions and calculated the area using ImageJ (http://imagej.nih.gov/ij/).

Confocal immunofluorescence. For each animal and hemisphere, we selected sections in PM and M1 in which the EYFP labeling was the strongest (according to the immunoperoxidase labeling), which is indicative of strong opsin expression. The sections were treated with antibod- 
ies against EYFP and NeuN to reveal opsin-positive elements and neurons, respectively. These experiments helped to confirm the neuronal phenotype and estimate the proportion of opsin-positive cells.

We also used confocal immunofluorescence to study the relation between opsin-positive corticothalamic terminals and the different subtypes of thalamic neurons. Sections adjacent to those enriched in EYFPpositive cortical terminals in the thalamus (based on immunoperoxidase labeling) were incubated with antibodies against EYFP to reveal opsinpositive elements, antibodies against CaMKII $\alpha$ to identify CaMKII $\alpha$ positive corticothalamic neurons, and antibodies against GABA to label GABA-positive interneurons.

Sections were incubated for $24 \mathrm{~h}$ in a mixture of anti-EYFP (see above) and anti-NeuN (raised in mouse, 1:1000, catalog \#MAB377; Millipore) or anti-EYFP, anti-CaMKII $\alpha$ (made in mouse, 1:15,000, catalog \#AB22609; AbCam) and anti-GABA (made in rabbit, 1:1000, catalog \#A-2052; Sigma-Aldrich) for the triple immunofluorescence experiments. Sections were then exposed to the secondary fluorescent antibodies (anti-chicken fluorescein to reveal EYFP in green; anti-mouse rhodamine Red-X to reveal NeuN or CaMKII $\alpha$ in red; anti-rabbit DyLight 405 to reveal GABA in blue, all secondary antibodies at 1:100 concentration; Jackson Immunoresearch).

The sections were then mounted with Vectashield (Vector Laboratories) and examined using a confocal laser scanning microscope (Leica DM5500B) equipped with a CCD camera (Orca R2; Hamamatsu).

We scanned the sections to determine the area where the green fluorescence (indicating opsin expression) was the highest. All selected areas were within $1.5 \mathrm{~mm}$ from the nearest injection track. From 2 nonoverlapping fields $\left(0.15 \mathrm{~mm}^{2}\right.$ each) in this region, we acquired optical sections in the confocal microscope to create a digital stack (71-130 optical sections per image). The stacks were examined in ImageJ to count the number of red (NeuN-positive) and green (EYFP-positive) cell bodies. Average results were obtained from quantitative data collected in triplicates of each image stack.

Electron microscopy. We used preembedding immunoperoxidase and immunogold methods to analyze the subcellular localization of opsins on corticothalamic terminals and their relationship to other thalamic elements. For electron microscope (EM) processing, we selected sections adjacent to those in which we could distinguish clear immunoperoxidase labeling of putative corticothalamic terminals in the immunoperoxidase material prepared for the light microscope. Due to poor ultrastructural preservation in brain tissue from monkey W, we restricted the EM analysis to material from monkey $\mathrm{V}$.

For preembedding immunoperoxidase, sections were processed for EM as described previously (Galvan et al., 2010, 2012; Galvan et al., 2014). We used the same antibodies as for light microscopy (see above) except that the exposure time to the anti-EYFP primary antibodies was $48 \mathrm{~h}$.

In other sections, immunoperoxidase was used, as before, to reveal EYFP-positive elements and gold particles were used to reveal GABApositive elements. The purpose of these experiments was to evaluate the incidence of opsin-expressing cortical terminals in contact with GABAergic elements (putative interneurons) in the thalamus. Sections were immersed in PBS containing 5\% nonfat dry milk for $30 \mathrm{~min}$ and washed in TBS-gelatin buffer (Tris $0.02 \mathrm{M}, \mathrm{NaCl} 0.15 \mathrm{M}$, and $0.1 \%$ cold water fish gelatin). After incubation in a solution containing anti-EYFP (made in chicken, 1:2000, catalog \#06-896; Millipore) and anti-GABA (see above), the sections were rinsed in TBS-gelatin and incubated in a mixture of secondary antibodies (biotinylated anti-chicken, 1:200, Vector Laboratories, and gold-conjugated anti-rabbit, 1:100, Nanoprobes). All antibodies were diluted in TBS-gelatin buffer containing $1 \%$ dry milk. The sections were then washed with TBS-gelatin and $2 \%$ acetate buffer and the gold particles were silver intensified (HQ silver; Nanoprobes) for 9-13 $\mathrm{min}$. The process was stopped by washes in acetate buffer and TBS-gelatin for $10 \mathrm{~min}$. To reveal the biotinylated antibodies, the sections were then incubated in ABC solution (1:200 in TBS-gelatin solution containing with $1 \%$ milk for $90 \mathrm{~min}$ ) and rinsed with TBS-gelatin and Tris (0.05 M, pH 7.4). The tissue was then postfixed (OsO4 0.5\%, 0.1 $\mathrm{M} \mathrm{PB}, \mathrm{pH} 7.4$ ) for $10 \mathrm{~min}$, dehydrated, exposed to $1 \%$ uranyl acetate for $10 \mathrm{~min}$, and embedded in resin (Durcupan ACM; Sigma-Aldrich). We selected blocks containing EYFP-enriched areas in the BGMT, CbMT, and RT (at least two blocks of tissue per area) and obtained 60-nm-thick ultrathin sections (Ultracut T2; Leica), which were collected on pioloform-coated copper grids.

We examined the sections with an EM (JEOL model 1011) at 20,000$25,000 \times$ and acquired digital micrographs of fields containing immunoreactive elements (DualView 300W camera controlled by Digital Micrograph software version 2.32.888; Gatan). An area of $1260 \mu \mathrm{m}^{2}$, $3700 \mu \mathrm{m}^{2}$, and $800 \mu \mathrm{m}^{2}$ was examined for the BGMT, CbMT, and RT, respectively (better tissue preservation in CbMT regions allowed for a larger area to be examined) and at least two blocks per region were included in the analysis. The data from the left and right hemispheres (transfected with C1V1 and ChR2, respectively) were pooled together.

We categorized the immunopositive structures into dendrites, terminals, unmyelinated preterminal axons, myelinated axons, and glial processes based on ultrastructural features (Peters et al., 1991). Immunoreactive elements that could not be categorized based on their ultrastructural features remained unidentified. The relative proportion of each category of labeled elements was calculated and expressed as percentage of total labeled elements in the areas examined, as described previously (Galvan et al., 2004; Galvan et al., 2010; Galvan et al., 2012). Using previous criteria (Ilinsky and Kultas-Ilinsky, 1990; Kultas-Ilinsky and Ilinsky, 1991), the immunopositive axonal terminals were classified as "small bouton with round vesicles" (SR) or "large bouton with round vesicles" based on their morphological features [shape of the terminal, type of synaptic contact established, type of vesicles (round or flattened) and number of mitochondrion] and the surface area of the terminal. The area was obtained by tracing the border of the element in the micrograph and calculating the surface area with ImageJ (this was done in boutons with well defined and uninterrupted membrane borders).

To determine whether opsin-positive terminals were in contact with GABAergic elements, we examined $400 \mu \mathrm{m}^{2}$ in BGMT (1 block) and 720 $\mu \mathrm{m}^{2}$ in CbMT (2 blocks) of tissue treated with immunoperoxidase to reveal EYFP-positive elements and gold particles to reveal GABA. An element was defined as GABA-positive if the density of gold particles was above the mean +2 SD of the density of gold particles found in EYFPpositive (assumed to be glutamatergic) terminals present in this material. We determined the proportions of EYFP-positive terminals with identifiable asymmetric synaptic in contact with GABA-positive elements. Data are expressed as means $\pm \mathrm{SD}$.

\section{Results}

\section{Light stimulation of cortical neurons and corticothalamic terminals}

Database

We used optrodes to record the extracellular activity of cortical neurons (in M1 and PM) or thalamic neurons (in BGMT or CbMT) while light activating the opsins expressed at the level of cell bodies or axon terminals of cortical neurons. The recorded neurons were identified to be in the PM, M1, BGMT, or CbMT based on the location of the optrode tracks in the histological examination (see Materials and Methods). Recordings outside of these areas were not considered. After discarding recordings that were of low quality and in which spike trains could not be sorted according to our quality criteria (see Materials and Methods), our analysis included 110 cortical neurons, 150 neurons in the BGMT, and 67 neurons in CbMT. The results from both monkeys were combined.

\section{Overall effectiveness of light stimulation and comparison of the effects obtained with C1V1 and ChR2}

We observed light-modulated neuronal activities in large proportions of cortical and thalamic neurons after expression of both C1V1 and ChR2 opsins. C1V1-transfected regions yielded larger proportions of responses in cortex $(82 \%$ and $44 \%$ of all neurons tested responded to light stimulation in C1V1 and ChR2 areas, respectively, $p=0.001$, Pearson $\left.\chi^{2}\right)$ and in BGMT $(68 \%$ 

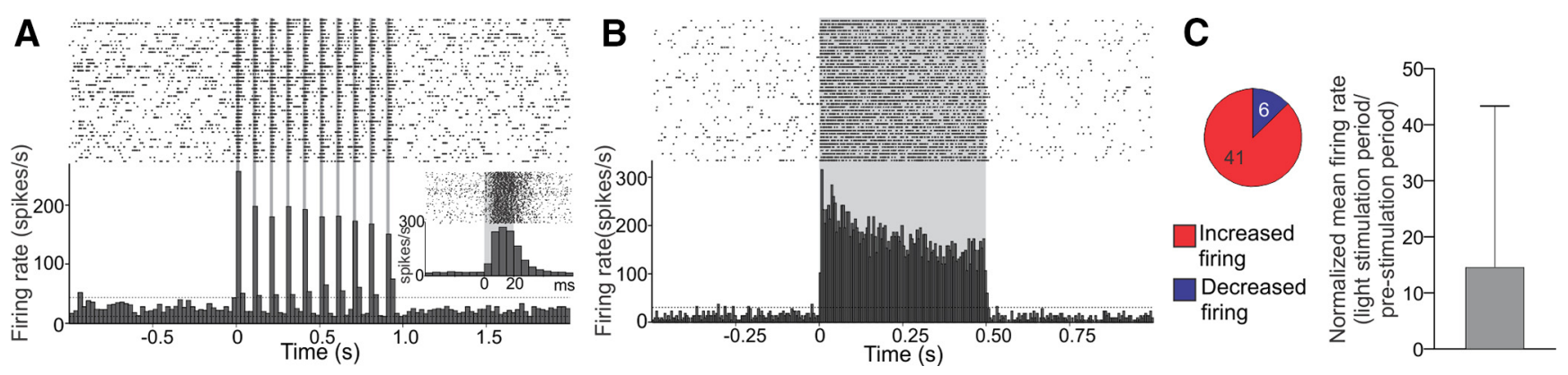

Figure 1. Responses of cortical neurons to opsin activation. $A$, Raster diagram and PSTH of a single unit in primary motor cortex (M1) showing responses to light stimulation of ChR2 (10 pulses, $20 \mathrm{~ms} / \mathrm{pulse}, 10 \mathrm{~Hz}$ ). The raster diagram and peristimulation time histogram (PSTH) are aligned to the start of the trains of light pulses. Each bin in the PSTH display is $25 \mathrm{~ms}$ in duration. Inset, Raster diagram and PSTH aligned to the start of each pulse in the train. Each bin is $5 \mathrm{~ms}$ in duration. $\boldsymbol{B}$, PSTH of the same cell in $\boldsymbol{A}$ showing responses to $500 \mathrm{~ms}$ light pulses (note different time scale in this figure). Each bin is $5 \mathrm{~ms}$ in duration. The dashed horizontal lines in $A$ and $\boldsymbol{B}$ indicate 2 SDs above and below the baseline bin average (calculated based on data collected $1 \mathrm{~s}$ and $0.5 \mathrm{~s}$ before the start of light stimulation for $\boldsymbol{A}$ and $\boldsymbol{B}$, respectively) and the shaded gray areas indicate the light pulses. $\boldsymbol{C}$, Left, Proportion of cortical neurons with increased or decreased firing rates in response to the light stimulation (numbers of cases indicated). Right, Change in firing rate during light stimulation normalized to the firing rate in the control period for cortical neurons that responded to the $500 \mathrm{~ms}$ light pulse (mean + SD). Responses to C1V1 and ChR2 were pooled for the graphs in $\mathbf{C}$.

and $48 \%$ of neurons were modulated by light stimulation of the C1V1- and ChR2-transfected terminals, respectively, $p=0.015$, Pearson $\chi^{2}$ ). In the CbMT, the proportions of neurons that responded to light stimulation of the corticothalamic terminals were similar in C1V1- and ChR2-expressing areas (57\% and 54\%, respectively).

The proportions of types of responses (decreases or increases in firing) obtained were similar with the two opsins in each of the brain regions examined. To further verify that the changes in firing were evoked by the opsin activation, we generated sham PSTHs in which the spikes were aligned to randomly expected events. As expected, we did not find any significant change in firing in these histograms.

\section{Responses of cortical neurons to opsin activation}

The light stimulation strongly affected the firing of cortical neurons in response to either trains of short light pulses (10 pulses, 20 ms/pulse, $10 \mathrm{~Hz}$; Fig. 1A) or to single $500 \mathrm{~ms}$ pulses (Fig. 1B). Although a few neurons showed inhibitory responses, the mean firing rate of all light-modulated cortical neurons was strongly increased during the optical activation (Fig. 1C).

These results, including the presence of some inhibitory responses, are in agreement with previous reports of neuronal modulation by ChR2 or C1V1 activation in cortical regions in monkeys (Han et al., 2009; Diester et al., 2011; Ozden et al., 2013; Lu et al., 2015; Nassi et al., 2015).

As reported previously (Diester et al., 2011), the optical stimulation in motor cortex did not induce any movements in the animals. This was evaluated during two optical stimulation sessions with monkey $\mathrm{W}$ in which light stimulation from an optrode lowered into a C1V1-transfected M1 area evoked strong neuronal responses.

\section{Responses of thalamic neurons to opsin activation}

When the opsins expressed on corticothalamic terminals were activated, the resulting responses in BGMT and CbMT neurons were more varied than what we have found in cortex, including increases (Fig. 2A) and reductions in firing (Fig. 2B).

In the BGMT, $55 \%$ and $45 \%$ of the responding neurons showed increases and decreases in firing, respectively. In CbMT, the corresponding proportions were $46 \%$ and $54 \%$, respectively (the distributions of responses between BGMT and CbMT regions were not statistically different, $p=0.42$ Pearson $\chi^{2}$ ). The mean firing rate of all light-responsive BGMT and CbMT neurons was slightly decreased during the light stimulation (Fig. 2C).
In the thalamus, trains of short light pulses (10 pulses, $20 \mathrm{~ms} /$ pulse, $10 \mathrm{~Hz}$ ) had little effect on neuronal spiking. Only three of 59 BGMT neurons tested with these parameters showed changes in firing (two neurons responded with an increase and one with a decrease in firing) and, of 11 CbMT neurons tested with these stimulation conditions, none responded.

\section{Localization of thalamic neurons that responded to the light stimulation}

In both thalamic areas, the polarity of light-evoked responses was not dependent on the location within the nucleus. Except for very few cases, there was generally no clustering of responses along the optrode tracks, as shown in the examples in Figure $3 A$. Instead, neurons separated by a few hundred micrometers, or sometimes recorded at the same electrode location, displayed different responses (Fig. $3 B, C$ ).

Time course and relationship between neuronal responses and the intensity of light stimulation

We compared the latency to a light-evoked change in firing of cortical and thalamic neurons. Because short (20 ms) light pulses did not have an effect on most thalamic neurons, we limited this analysis to cortical and thalamic neurons tested with $500 \mathrm{~ms}$ light pulses.

The delay between the onset of stimulation and the evoked responses in recorded cells was shorter for cortical recordings during intracortical opsins activation than for thalamic neuron recordings when we activated opsins in corticothalamic terminals. In the cerebral cortex, excitatory responses had a mean latency of $44 \pm 105 \mathrm{~ms}$ and almost $50 \%$ of these responses occurred before $10 \mathrm{~ms}$ from the onset of the light pulse. In contrast, the latencies to excitatory responses in the thalamus were $218 \pm 120$ and $228 \pm 144 \mathrm{~ms}$ for BGMT and CbMT, respectively. In $>70 \%$ of BGMT and CbMT neurons, the latency from the onset of light stimulation was $>100 \mathrm{~ms}$ (Fig. 4A). Similarly, inhibitory responses took longer to develop when the corticothalamic terminals were stimulated (although only few cortical neurons responded with reductions in firing rate to light stimulation). The mean latency to induce an inhibitory response in cortical neurons was $133 \pm 147 \mathrm{~ms}$, whereas it took $219 \pm 130$ and $211 \pm 96 \mathrm{~ms}$ of light stimulation to evoke a decreased in firing in BGMT and CbMT, respectively (Fig. 4B).

In some recordings, we tested the responses to different light intensities, testing the range $60-820 \mathrm{~mW} / \mathrm{mm}^{2}$. For this analysis, we pooled excitatory and inhibitory responses from five cortical and six 

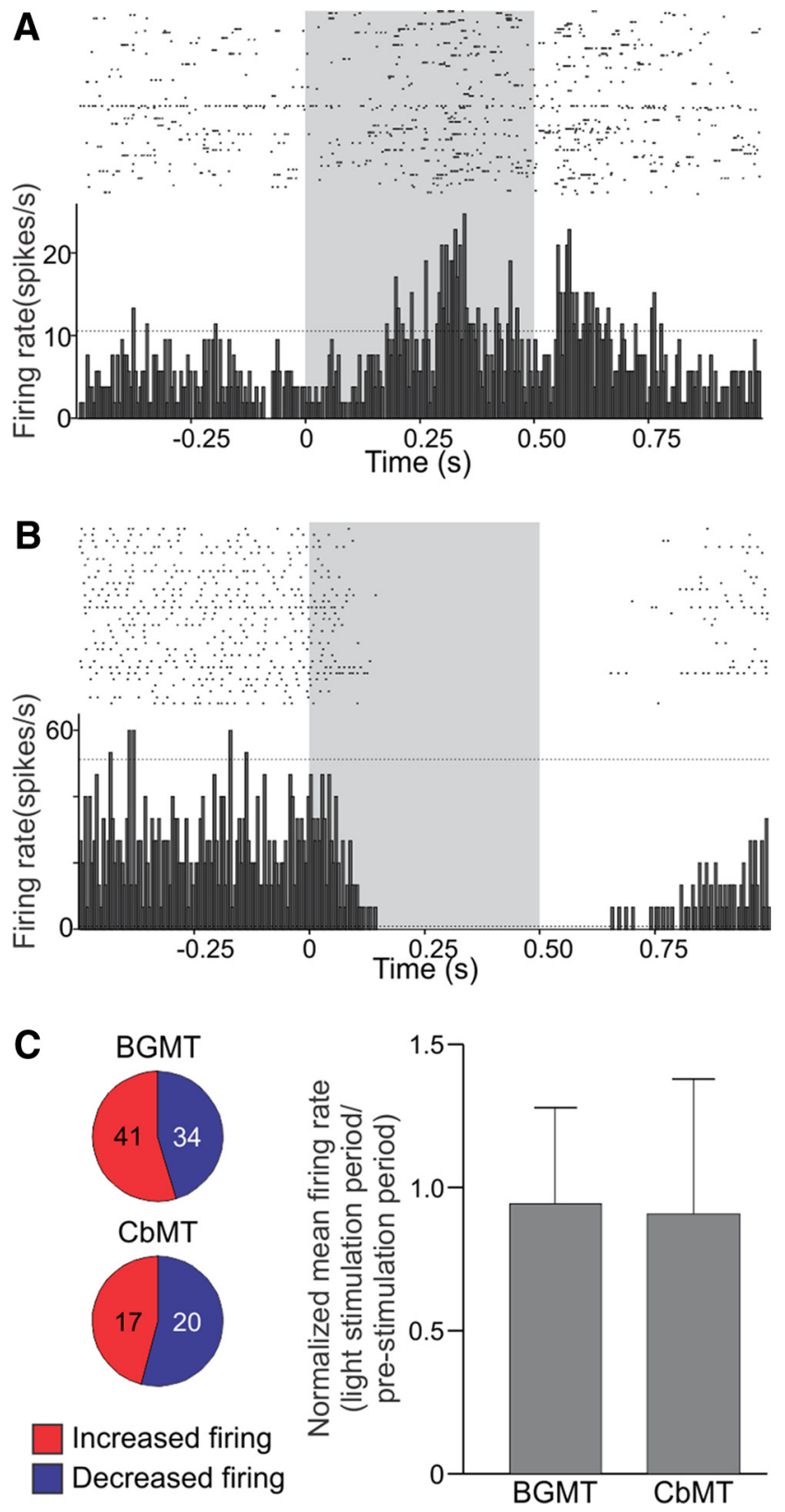

Figure 2. Responses of thalamic neurons to activation of opsins on corticothalamic axons. $\boldsymbol{A}$, Raster diagram and PSTH of a single unit in basal ganglia-receiving motor thalamus (BGMT). The cell showed an increase in firing during the activation of ChR2. The raster diagram and PSTH are aligned to the start of the light pulse. $\boldsymbol{B}$, Cerebellar-receiving motor thalamus (CbMT) neuron showing a decrease in firing during the activation of ChR2. For both $\boldsymbol{A}$ and $\boldsymbol{B}$, each bin is $5 \mathrm{~ms}$ in duration. Dashed horizontal lines indicate 2 SDs above and below the baseline (based on the cell's firing during the 0.5 s before the start of each stimulus). The gray shaded areas indicate the presence of the light pulses. $\boldsymbol{C}$, Left, Proportion of BGMT and CbMT neurons that increased or decreased firing in response to the light stimulation (number of cases are indicated). Right, Ratio of firing rates during the light pulse and the preceding control periods for neurons in BGMT and CbMT with firing that was modulated by the 500 ms light pulse (mean + SD). Responses to C1V1 and ChR2 were pooled for the graphs in $C$.

thalamic (including both BGMT and CbMT) neurons. These tests were done only with recordings in the C1V1-transfected hemispheres. As shown in Figure $4 C$, the minimal light intensity required to achieve changes in firing during light stimulation was much lower with the somatic stimulation in cortex $\left(126 \pm 50 \mathrm{~mW} / \mathrm{mm}^{2}\right)$ than with the stimulation of cortical terminals in the thalamus $(632 \pm 228$ $\mathrm{mW} / \mathrm{mm}^{2}$ ).

\section{A Olncreased firing ODecreased firing ONo change}
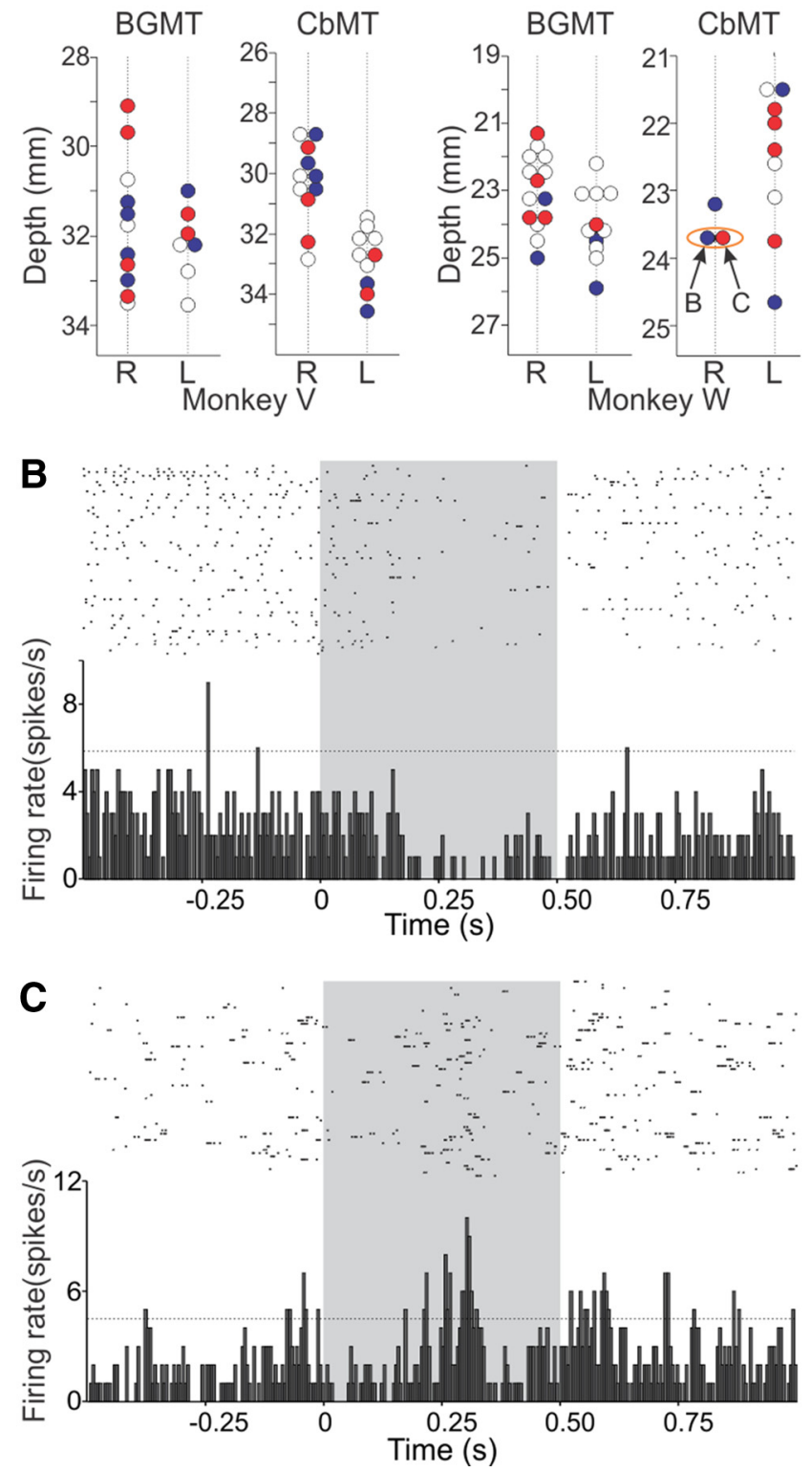

Figure 3. Location of thalamic neurons recorded during light stimulation. $\boldsymbol{A}$, Each circle indicates a single thalamic neuron recorded during light stimulation. One example optrode track (dashed lines) per hemisphere ( $R$ and $L$ indicate the right and left hemisphere, respectively) is shown for each thalamic region in the two monkeys. Light-stimulation-induced increases are shown as red circles, decreases as blue circles, and cells with activity that was not changed by the stimulation are shown as open circles. Note that cells with increases, decreases, and no response to light were found in close proximity to one another. $\boldsymbol{B}, \boldsymbol{C}$, Raster diagram and PSTH of two neurons that were recorded at the same electrode location (depth $=23.7$ ) in the CbMT of monkey W (indicated with an orange circle in $\boldsymbol{A}$ ). The cell in $\boldsymbol{B}$ showed a decrease in firing during the stimulation and the neuron in $\boldsymbol{C}$ responded with increased firing to the opsin activation. Raster and PSTH conventions are the same as in Figure 2.

\section{Expression of opsins in cortex and motor thalamus}

Light microscopy observations

Using antibodies against GFP (which recognize EYFP, the tag protein fused to ChR2 or C1V1), strong expression of ChR2 or C1V1 was identified in M1 and PM of both animals. We found that the total transfected area extended between interaural levels 21 and 12 in the Paxinos brain atlas (Paxinos et al., 2000) and to a maximum of $5 \mathrm{~mm}$ mediolaterally. As expected, the strongest 

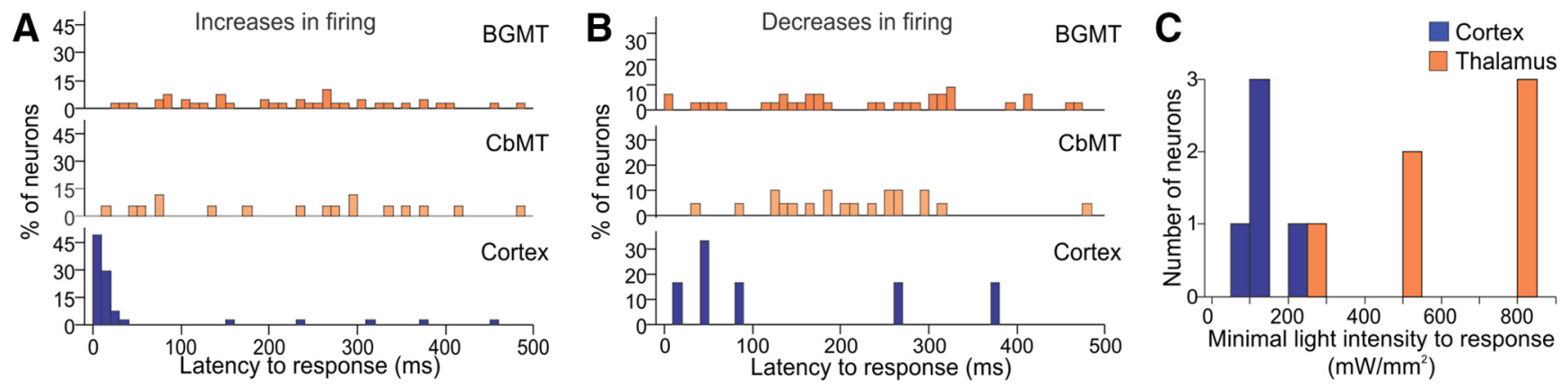

Figure 4. Time course and dependence of neuronal responses on the intensity of light stimulation in motor cortex and thalamus. $A, B$, Latencies to show increased $(\boldsymbol{A})$ or decreased $(\boldsymbol{B})$ firing in response to a light pulse; each bin is $10 \mathrm{~ms}$ long. C1V1 and ChR2 cases were combined. C, Minimal light intensity needed to evoke significant changes in firing rates of thalamic and cortical neurons. The histogram includes only responses to C1V1 activation.
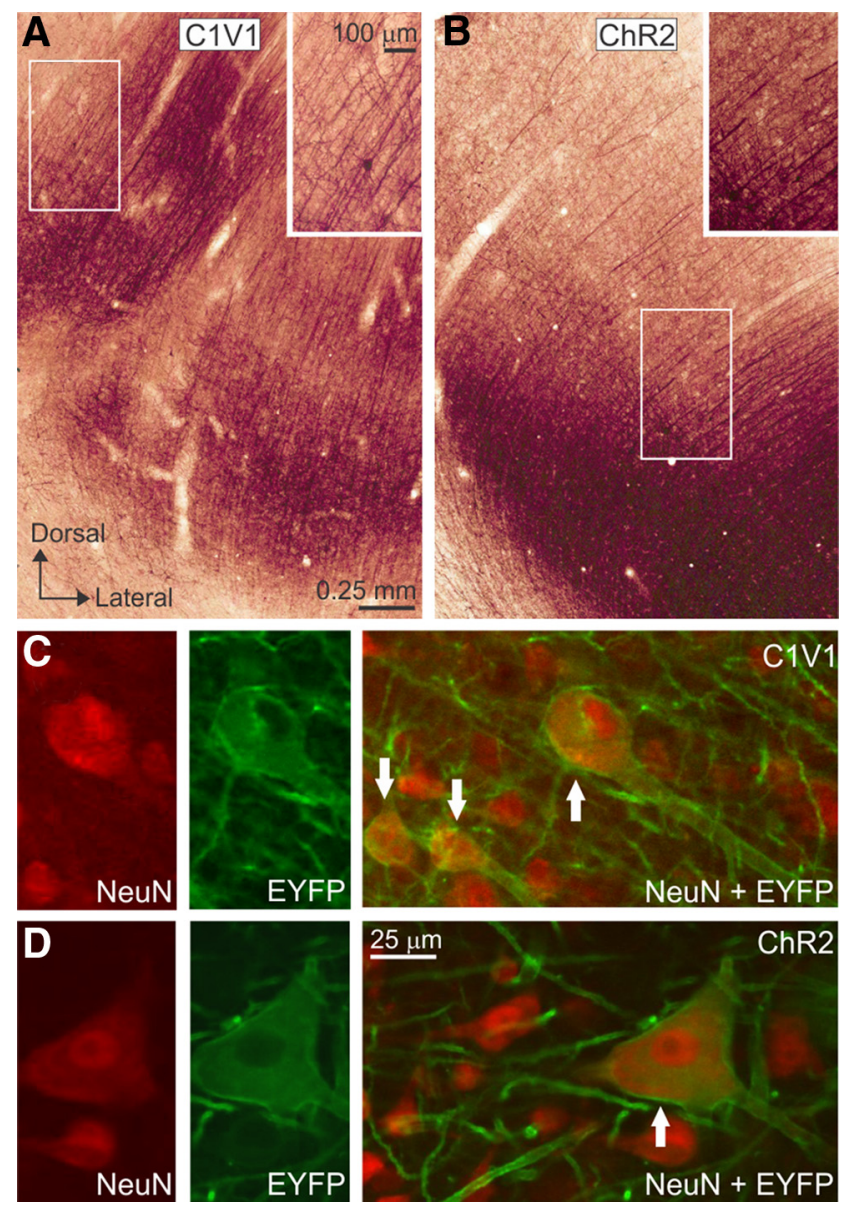

Figure 5. $\quad A, B$, Immunoperoxidase labeling of EYFP indicating C1V1 and ChR2 expression at the sites of virus injections in the primary motor cortex. Areas in rectangles are shown at higher magnification in the insets. $\boldsymbol{C}, \boldsymbol{D}$, Immunofluorescence labeling indicating NeuN-positive (red) and C1V1-positive or ChR2-positive (green) cells in M1. Cells that show colocalization are indicated by arrows. Orientation of tissue and scale bars in $\boldsymbol{A}$ (including insets) also apply to $\boldsymbol{B}$. Scale bar in $\boldsymbol{D}$ also applies to $\boldsymbol{C}$.

opsin expression was found in deep cortical layers (layers $\mathrm{V}$ and VI; Fig. $5 A, B$ ).

To identify the type of opsin-expressing cells and to estimate the proportion of cells transfected in the injected areas, we used a double immunofluorescence labeling approach with antibodies against NeuN (to recognize neuronal cell bodies) and EYFP (to identify cells expressing the opsin). In the areas closest to the injection tracks, where the opsin expression was expected to be highest, $\sim 10 \%$ and $5 \%$ of NeuN-positive profiles in the cerebral cortex expressed EYFP in C1V1 and ChR2 material, respectively (Fig. 5C,D). These proportions, however, are most likely an underestimate of the neurons expressing opsins because EYFPpositive cell bodies can be masked by the overwhelming expression of EYFP along the dendritic trees. We did not find any EYFP-positive/NeuN-negative profiles as evidence that the opsins were expressed exclusively in neurons.

Expression of opsins was also clearly identified in cortical axons along the internal capsule (Fig. 6A,B) and in targets of motor cortices, including the motor thalamus (see below), and other subcortical targets (i.e., subthalamic nucleus, red nucleus).

After injection of either C1V1 or ChR2 in cortex, the motor thalamus showed robust immunoperoxidase labeling both in BGMT and CbMT (Fig. 6A,B). The pattern of the cortical terminals in the thalamus was reminiscent of that described after injections of anterograde tracers in motor cortices (McFarland and Haber, 2002). We also observed opsin-positive fibers in the RT. We did not find expression of C1V1 or ChR2 on neuronal and glial cell bodies in the thalamus, indicating the lack of thalamic retrograde transport and nonspecific glial contamination induced by the cortical injections of the virus solution.

To discern the spatial relationships between opsin-positive corticothalamic terminals and subtypes of thalamic neurons, we used a triple fluorescence approach in which thalamocortical neurons were labeled with antibodies against CaMKII $\alpha$ (Benson et al., 1991), GABAergic interneurons and terminals were identified with antibodies against GABA, and opsin-positive corticothalamic axons were visualized with antibodies against EYFP (red, blue, and green elements, respectively; Fig. 6C). In these sections, opsin-positive terminal-like varicose processes were rarely apposed to CaMKII $\alpha$ - or GABA-positive somas, but rather were distributed within the rich meshwork of CaMKII $\alpha$ - and GABA-positive processes, suggesting interactions with dendrites of thalamic neurons. These observations were confirmed in EM experiments.

\section{EM observations}

We used preembedding immunoperoxidase and EM observations to analyze the subcellular localization of opsins in the thalamus. In the area of tissue examined, we found 131 and 722 EYFP-positive elements in the BGMT and CbMT, respectively. The larger number of elements in CbMT reflects the larger area we were able to sample in this region (see Materials and Methods) and the fact that the density of labeled elements per area was higher in the CbMT than in the BGMT (0.19 and 0.10 labeled elements $/ \mu \mathrm{m}^{2}$, respectively). However, the type of EYFP-positive 

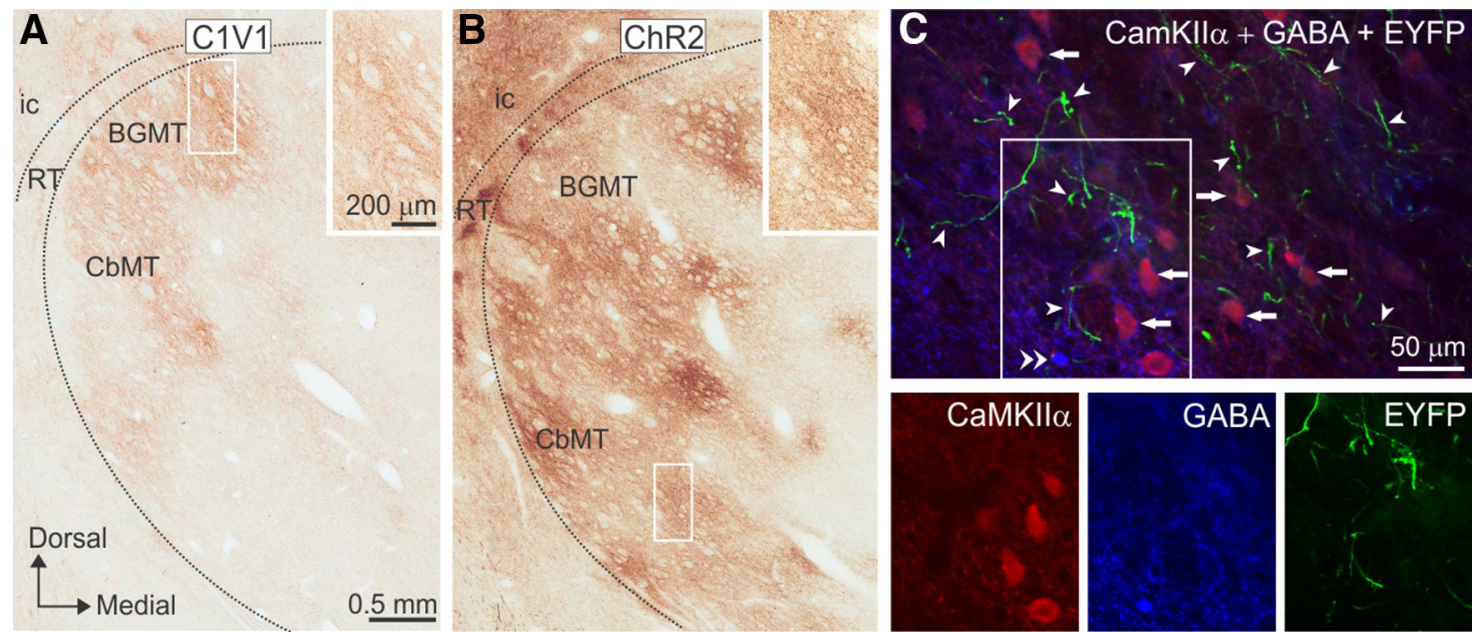

Figure 6. $A, B$, Immunoperoxidase labeling for EYFP indicating C1V1 and ChR2 expression in the thalamus. Areas in rectangles are shown at higher magnification in the insets. $C$, Immunofluorescence labeling indicating CaMKII $\alpha$-positive (red), GABA-positive (blue), and EYFP-positive (green) elements in BGMT (section adjacent to the one shown in $\boldsymbol{B}$ ). CaMKII $\alpha$ positive corticothalamic neurons are indicated by arrows; EYFP-positive corticothalamic axons (EYFP positivity is indicative of opsin expression) are indicated by arrowheads; a GABA-positive soma (putative interneuron) is indicated by double arrowheads. The area in the rectangle is shown for each immunofluorescence marker at the bottom. Note that the opsin-containing varicose processes do not come in close contact with CaMKII $\alpha$-positive or GABA-positive cell bodies, suggesting that these putative corticothalamic terminals might contact the dendritic tree of thalamic cells. ic, Internal capsule; RT, reticular thalamus. Orientation of tissue and scale bars in $\boldsymbol{A}$ (including insets) also apply to $\boldsymbol{B}$.

elements was similar in both regions. Preterminal axons accounted for $48 \%$ and $50 \%$ of all labeled elements, whereas axon terminals represented $32 \%$ and $20 \%$ of labeled elements in BGMT and CbMT, respectively (Fig. $7 A, B$ ). Therefore, the large majority of opsin-positive elements were presynaptic. In either region, most of the remaining labeled elements were myelinated axons or unknown structures; $<3 \%$ of EYFP-positive elements were identified as dendrites.

We selected axonal terminals with well defined borders to examine their morphological features and calculate the surface area (27 and 72 EYFPpositive terminals were selected in the BGMT and CbMT, respectively). The opsin-positive terminals were small $\left(0.28 \pm 0.17 \mu \mathrm{m}^{2}\right.$ in BGMT and $0.35 \pm$ $0.41 \mu \mathrm{m}^{2}$ in (bMT) and most of them contained many round vesicles and $\leq 1$ mitochondrion. When the synaptic contacts could be visualized in single ultrathin sections, it was single, of the asymmetric type, and involved small- or medium-sized dendrites $(<1 \mu \mathrm{m}$ in diameter). These morphological features and pattern of synaptic connection correspond to those of the SR cortical terminals described in previous monkey studies in the motor thalamus (Ilinsky and Kultas-Ilinsky, 1990; Kultas-Ilinsky and Ilinsky, 1991; Rovó et al., 2012) and fulfill the anatomical criteria of "modulatory" corticothalamic terminals (Sherman, 2012). We did not encounter any EYFP-labeled terminals that displayed the
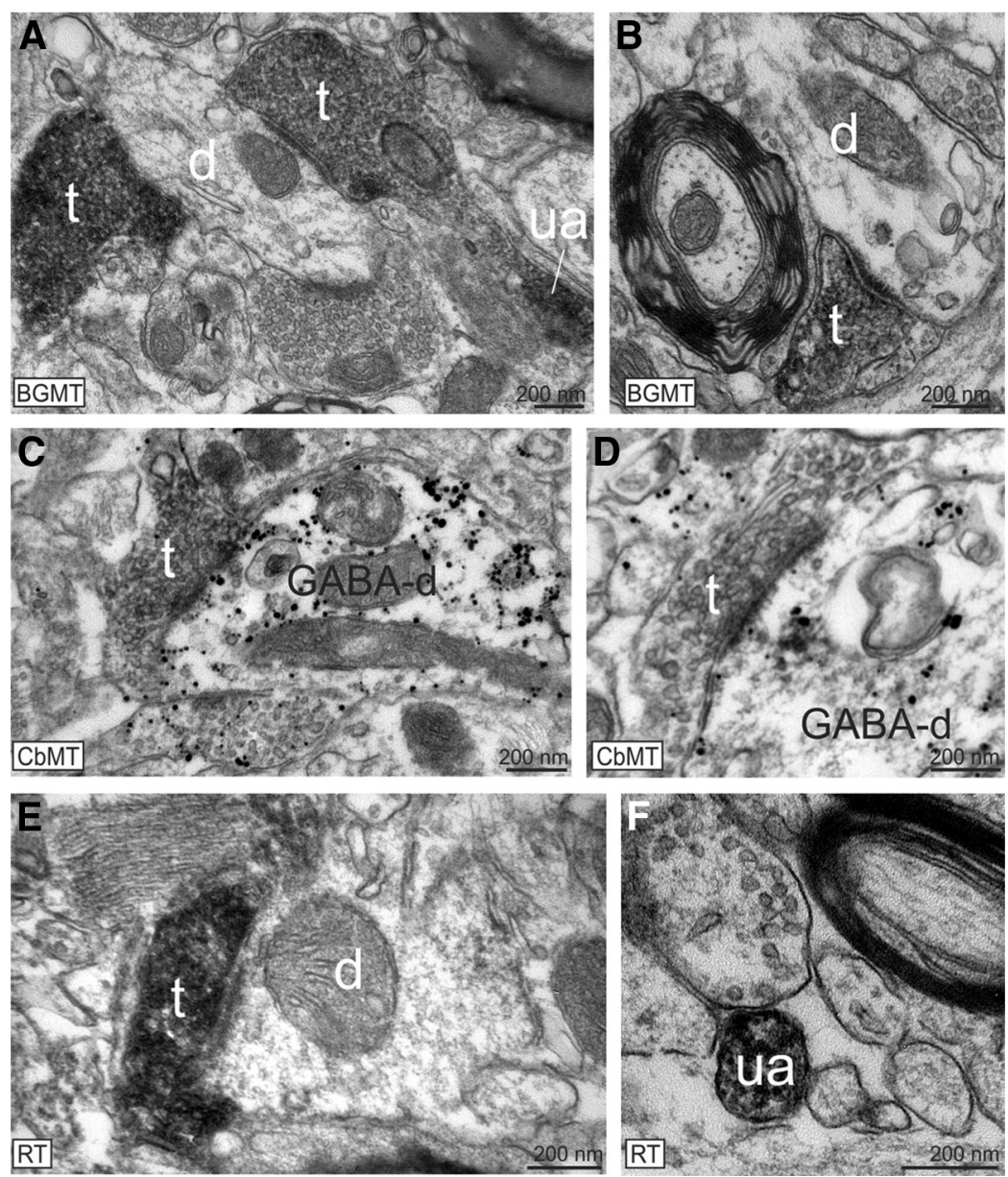

Figure 7. Opsin-positive corticothalamic terminals and axons in the motor thalamus. $\boldsymbol{A}, \boldsymbol{B}$, Examples of EYFP-positive (ChR2-expressing) terminals (t) contacting dendrites (d) in BGMT. A ChR2-positive unmyelinated preterminal axon (ua) is shown in $\boldsymbol{A}$. C, D, ChR2-expressing corticothalamic terminals (t) contact GABA-positive dendrites (GABA-d) of putative interneurons in CbMT. E, ChR2-positive terminal (t) contacting a dendrite (d) in the RT. $\boldsymbol{F}$, Unmyelinated preterminal axon that is positive for C1V1 (ua) in the RT. 
ultrastructural features of "driver-like" glutamatergic terminals (Rovó et al., 2012) in BGMT or CbMT.

Given the abundance of thalamic neurons that responded to the light stimulation with decreases in firing, we explored whether opsin-expressing cortical terminals contacted dendrites of GABAergic interneurons, which constitute $20-25 \%$ of all thalamic neurons in primates (Smith et al., 1987; Ilinsky and Kultas-Ilinsky, 1990; Sherman, 2004; Jones, 2007) and are known to receive contacts from cortical projections (Ilinsky and Kultas-Ilinsky, 1990; Kultas-Ilinsky and Ilinsky, 1991) in the monkey ventral motor thalamus. To this end, we used gold particles to label GABA and peroxidase to reveal EYFP. In this material, we found 17 ChR2-positive terminals (five in BGMT and 12 in CbMT) in synaptic contact with dendritic elements and seven of these terminals (all in CbMT) contacted GABApositive dendrites putatively belonging to thalamic interneurons (Fig. $7 C, D$ ). These observations support the possibility that activation of corticothalamic terminals could drive GABAergic interneurons.

Another source of GABA in the motor thalamus are afferents from the RT (Pinault, 2004), which receives axon collaterals from corticothalamic layer VI projections (Rouiller and Welker, 2000; Kakei et al., 2001; Sirota et al., 2005). To verify whether opsinpositive corticothalamic afferents were present in the RT, we selected blocks of tissue from the RT and prepared them for EM observations. In this tissue, we found 133 EYFP-positive elements (0.17 labeled elements $/ \mu \mathrm{m}^{2}$ ). Of these, $73 \%$ were preterminal unmyelinated axons and terminal boutons constituted the second-largest group (10\%) of EYFP-positive elements (Fig. $7 E, F)$. Unidentifiable profiles or myelinated axons constituted the rest of the labeled elements. We examined the morphological features of 11 opsin-positive terminals in the RT. These have the aforementioned characteristics of SR cortical terminals (surface area $0.53 \pm 0.31 \mu \mathrm{m}^{2}$ ) and, when synaptic contacts were visible, they were found to be asymmetric (Fig. 7E).

\section{Discussion}

We found that in vivo optical activation of opsin-containing corticothalamic terminals arising from PM and M1 modulates activity of thalamic neurons in the awake primate brain. In contrast to the robust, light-induced, short-latency increases in firing observed in the transfected cortical regions, activation of ChR2- and C1V1-positive corticothalamic terminals resulted in long-latency increases or decreases in firing of BGMT and CbMT neurons. The polarity and the long latencies of these responses, combined with our ultrastructural data, suggest the recruitment of intrathalamic GABAergic circuits from RT and GABAergic interneurons by corticothalamic afferents.

\section{Opsin activation in motor cortex}

Extracellular recordings during optical stimulation of ChR2 and C1V1 expressed at the level of soma and dendrites in M1 and PM confirmed successful opsins expression in these regions. For both opsins, we frequently found cortical neurons in which the firing rate was modulated by light stimulation. The type and magnitude of these responses (including a few cortical neurons with inhibitory responses to light stimulation) are in agreement with results of previous optogenetic studies in monkeys (Han et al., 2009; Diester et al., 2011; Ohayon et al., 2013; Lu et al., 2015). The higher percentage of light-responding neurons found in brain regions transfected with $\mathrm{C} 1 \mathrm{~V} 1$ than with $\mathrm{ChR} 2$ is likely due to the higher light sensitivity of C1V1 (Mattis et al., 2012). However, parameters such as the polarity, magnitude, and latency of responses were not different between the two opsins, indicating that the differences in kinetics reported in in vitro experiments (Mattis et al., 2012) were not detected in our extracellular recordings in awake monkeys.

\section{Effects of activation of ChR2 and C1V1 expressed in axon terminals of corticothalamic neurons}

The activity of $\sim 50-70 \%$ of BGMT and CbMT neurons was modulated during optical stimulation of corticothalamic afferents. These responses, however, were heterogeneous and of long latency and therefore were difficult to reconcile with a monosynaptic effect. Intracellular recordings in rodent thalamus slices have shown that EPSPs are generated in thalamic neurons within $10 \mathrm{~ms}$ from the onset of electrical or optical stimulation of corticothalamic afferents (Golshani et al., 2001; Cruikshank et al., 2010), but these depolarizations are of relatively small amplitude (Cruikshank et al., 2010; Sherman, 2012). Therefore, in our studies, subtle depolarizations evoked in the recorded thalamic neurons by light stimulation of the corticothalamic fibers was likely insufficient to generate detectable short-latency spikes in extracellular recordings. At the same time, cortically induced EPSPs in thalamic neurons can be subject to temporal summation (Golshani et al., 2001). During the light pulses used in our experiments, temporal summation of small depolarizing events along the dendritic tree of the thalamic recipient neurons may have contributed to an eventually detectable increase in firing (a longer light pulse would also increase the chance of recruiting opsins that were initially in the desensitized state; Mattis et al., 2012).

Responses in thalamic neurons were only recorded with higher light intensities than those required to elicit responses in cortex, reflecting the fact that depolarization of individual opsinexpressing terminals (which have to trigger synaptic potentials to increase the firing of the neurons they terminate on) was subtle. In contrast, the effects of activation of somatic opsins in the cortex elicit a more direct effect on the target cell's membrane potential. As the light intensity increases, the volume of illuminated tissue expands, allowing for a larger number of opsin-expressing corticothalamic terminals to be activated.

Our data therefore indicate that activation of opsin-expressing corticothalamic terminals led to small depolarizations that required either temporal and/or spatial summation to increase neuronal firing. In addition, our EM observations showed that opsin-positive corticothalamic terminals in BGMT and CbMT formed synapses onto small (putatively distant) thalamic dendrites and displayed morphological features consistent with those reported for small corticothalamic terminals of layer VI origin (Kultas-Ilinsky and Ilinsky, 1991; Rouiller and Welker, 2000; Sherman, 2012). Conversely, "driver-like" glutamatergic terminals in the thalamus are large and form multiple synapses with distal and proximal dendrites of thalamic cells (Rovó et al., 2012; Sherman, 2012). In contrast to many thalamic nuclei, the BGMT is devoid of such afferents (Rovó et al., 2012), whereas the CbMT contains glutamatergic driver terminals from the deep cerebellar nuclei (Jones, 2007; Rovó et al., 2012). The lack of opsin-expressing "driver-like" terminals in the BGMT and CbMT is unlikely to be a consequence of selective expression of opsins in small cortical terminals because we found opsinexpressing neurons in layers V and VI of the cerebral cortex and noticed large, opsin-positive varicosities (putatively large axon terminals from layer $\mathrm{V}$ corticofugal neurons) in brain areas known to receive afferents from motor cortices (e.g., the red nucleus). Therefore, as suggested previously (Rovó et al., 2012), 
small corticothalamic terminals are the main sources of cortical modulatory glutamatergic control in the primate BGMT.

In many cases, light activation of opsin-containing glutamatergic corticothalamic terminals resulted in long latency decreases in firing in thalamic neurons. Similar observations were reported previously after electrical stimulation of corticothalamic neurons (Golshani et al., 2001; Steriade, 2001; Landisman and Connors, 2007; Lam and Sherman, 2010). This inhibition likely results from activation of GABAergic RT neurons by axon collaterals of layer VI corticothalamic cells (Rouiller and Welker, 2000; Kakei et al., 2001; Sirota et al., 2005). The action potential generated at the site of illumination in the BGMT and CbMT indeed may have propagated antidromically and then orthodromically along axon collaterals of layer VI corticothalamic axons to activate RT neurons, which in turn triggered inhibition in the recorded neurons. Our anatomical results support the existence of opsin-positive preterminal axons and terminal boutons in the RT. Because responses evoked by electrical or optical stimulation of corticothalamic axons are considerably stronger and more reliable in RT than in thalamic projection neurons (Golshani et al., 2001; Landisman and Connors, 2007; Cruikshank et al., 2010), it is likely that the RT-mediated GABAergic inhibition of BGMT and CbMT neurons prevails over the weaker direct corticothalamic EPSP (Destexhe et al., 1998; Golshani et al., 2001; Steriade, 2001; Cruikshank et al., 2010). Considering the attenuation of the light power in brain tissue (Ozden et al., 2013) and the spatial separation between the site of illumination in the motor thalamus and the RT, direct light diffusion from BGMT/ CbMT nuclei to the RT is unlikely.

Inhibitory responses can also originate from activation of thalamic GABAergic interneurons, which are relatively abundant in the monkey thalamus (Smith et al., 1987; Ilinsky and KultasIlinsky, 1990). Our EM findings indeed showed that some opsin-positive corticothalamic terminals contacted dendrites of GABAergic interneurons, which in turn may inhibit thalamocortical neurons through a dense meshwork of inhibitory dendro-dendritic synapses (Jones and Powell, 1969; Casale and McCormick, 2011; Jurgens et al., 2012; Cox, 2014). It is noteworthy that some thalamic neurons did not respond to the light stimulation even when delivered at high intensity. Although we cannot rule out that this simply reflected low expression of opsins in corticothalamic terminals, the fact that responding and nonresponding thalamic neurons were often found close together in regions with abundant opsin expression in corticothalamic terminals suggests that some thalamic neurons were insensitive to activation of cortical afferents.

The heterogeneity in responses of thalamic neurons to light stimulation (decreased or increased firing) may have been due to the specific pattern of cortical innervation to the recorded neuron (as suggested by the fact that neighboring neurons in the thalamus had opposite responses to the light stimulation), the state of excitability (Crandall et al., 2015), or the neuron's spontaneous activity at the time of stimulation (Goldberg et al., 2013).

The integration of motor-related information from cortical and subcortical inputs in the motor thalamus remains poorly understood (Bosch-Bouju et al., 2013). Afferents from the deep cerebellar nuclei can elicit short-latency excitatory responses in CbMT neurons (Chevalier and Deniau, 1982; Anderson and Turner, 1991; Nambu et al., 1991), whereas the inhibitory inputs from BGMT may "drive" the activity of thalamic neurons through rebound firing mechanisms (Person and Perkel, 2005), gating mechanisms (Deniau and Chevalier, 1985), or entrainment of neuronal firing (Goldberg and Fee, 2012). Studies in song birds indicate that, by modulating the ongoing activity of thalamocortical neurons, corticothalamic inputs influence the thalamic responses to subcortical inputs (Goldberg et al., 2013). Our studies suggest that the corticothalamic modulation involves intrathalamic circuits (RT afferents and, in primates, thalamic interneurons). The long latency response of thalamic neurons to corticothalamic activation could provide a time window in which subcortical inputs can influence the activity of thalamocortical neurons.

In summary, our results suggest that activation of the corticothalamic system in awake monkeys may have a modulatory (rather than a "driver") role in the activity of thalamic neurons with the potential of generating increases or decreases in firing and the latter may be driven by intrathalamic GABAergic networks.

\section{References}

Anderson ME, Turner RS (1991) Activity of neurons in cerebellar-receiving and pallidal-receiving areas of the thalamus of the behaving monkey. J Neurophysiol 66:879-893. Medline

Benson DL, Isackson PJ, Hendry SH, Jones EG (1991) Differential gene expression for glutamic acid decarboxylase and type II calcium-calmodulindependent protein kinase in basal ganglia, thalamus, and hypothalamus of the monkey. J Neurosci 11:1540-1564. Medline

Bodor AL, Giber K, Rovó Z, Ulbert I, Acsády L (2008) Structural correlates of efficient GABAergic transmission in the basal ganglia-thalamus pathway. J Neurosci 28:3090-3102. CrossRef Medline

Bosch-Bouju C, Hyland BI, Parr-Brownlie LC (2013) Motor thalamus integration of cortical, cerebellar and basal ganglia information: implications for normal and parkinsonian conditions. Front Comput Neurosci 7:163. Medline

Butler EG, Harvey MC, Finkelstein DI, Horne MK (1998) Neuronal activity in the monkey ventrolateral thalamus following perturbations of voluntary wrist movements. Exp Brain Res 118:393-407. CrossRef Medline

Canavan AG, Nixon PD, Passingham RE (1989) Motor learning in monkeys (Macaca fascicularis) with lesions in motor thalamus. Exp Brain Res 77: 113-126. Medline

Carrera E, Bogousslavsky J (2006) The thalamus and behavior: effects of anatomically distinct strokes. Neurology 66:1817-1823. CrossRef Medline

Casale AE, McCormick DA (2011) Active action potential propagation but not initiation in thalamic interneuron dendrites. J Neurosci 31:1828918302. CrossRef Medline

Chevalier G, Deniau JM (1982) Inhibitory nigral influence on cerebellar evoked responses in the rat ventromedial thalamic nucleus. Exp Brain Res 48:369-376. Medline

Cox CL (2014) Complex regulation of dendritic transmitter release from thalamic interneurons. Curr Opin Neurobiol 29:126-132. Medline

Crandall SR, Cruikshank SJ, Connors BW (2015) A corticothalamic switch: controlling the thalamus with dynamic synapses. Neuron 86:768-782. CrossRef Medline

Cruikshank SJ, Urabe H, Nurmikko AV, Connors BW (2010) Pathwayspecific feedforward circuits between thalamus and neocortex revealed by selective optical stimulation of axons. Neuron 65:230-245. CrossRef Medline

DeLong MR (1971) Activity of pallidal neurons during movement. J Neurophysiol 34:414-427. Medline

DeLong MR (1973) Putamen: activity of single units during slow and rapid arm movements. Science 179:1240-1242. CrossRef Medline

Deniau JM, Chevalier G (1985) Disinhibition as a basic process in the expression of striatal functions. II. The striato-nigral influence on thalamocortical cells of the ventromedial thalamic nucleus. Brain Res 334: 227-233. CrossRef Medline

Deschênes M, Labelle A, Landry P (1979) Morphological characterization of slow and fast pyramidal tract cells in the cat. Brain Res 178:251-274. CrossRef Medline

Deschênes M, Bourassa J, Pinault D (1994) Corticothalamic projections from layer $\mathrm{V}$ cells in rat are collaterals of long-range corticofugal axons. Brain Res 664:215-219. CrossRef Medline

Destexhe A, Contreras D, Steriade M (1998) Mechanisms underlying the 
synchronizing action of corticothalamic feedback through inhibition of thalamic relay cells. J Neurophysiol 79:999-1016. Medline

Diester I, Kaufman MT, Mogri M, Pashaie R, Goo W, Yizhar O, Ramakrishnan C, Deisseroth K, Shenoy KV (2011) An optogenetic toolbox designed for primates. Nat Neurosci 14:387-397. CrossRef Medline

Galvan A, Charara A, Pare JF, Levey AI, Smith Y (2004) Differential subcellular and subsynaptic distribution of $\mathrm{GABA}(\mathrm{A})$ and $\mathrm{GABA}(\mathrm{B})$ receptors in the monkey subthalamic nucleus. Neuroscience 127:709-721. CrossRef Medline

Galvan A, Hu X, Smith Y, Wichmann T (2010) Localization and function of GABA transporters in the globus pallidus of parkinsonian monkeys. Exp Neurol 223:505-515. CrossRef Medline

Galvan A, Hu X, Smith Y, Wichmann T (2012) In vivo optogenetic control of striatal and thalamic neurons in non-human primates. PLoS One 7:e50808. CrossRef Medline

Galvan A, Hu X, Rommelfanger KS, Pare JF, Khan ZU, Smith Y, Wichmann T (2014) Localization and function of dopamine receptors in the subthalamic nucleus of normal and parkinsonian monkeys. J Neurophysiol 112: 467-479. CrossRef Medline

Garber JC, Barbee RW, Bielitzki JT, Clayton LA, Donovan JC, Hendriksen CFM, Kohn DF, Lipman NS, Locker PA, Melcher J, Quimby FW, Turner PV, Wood GA, Wurbel H (2011) Guide for the care and use of laboratory animals, Ed 8. Washington, DC: National Academies.

Goldberg JH, Fee MS (2012) A cortical motor nucleus drives the basal ganglia-recipient thalamus in singing birds. Nat Neurosci 15:620-627. CrossRef Medline

Goldberg JH, Farries MA, Fee MS (2013) Basal ganglia output to the thalamus: still a paradox. Trends Neurosci 36:695-705. CrossRef Medline

Golshani P, Liu XB, Jones EG (2001) Differences in quantal amplitude reflect GluR4- subunit number at corticothalamic synapses on two populations of thalamic neurons. Proc Natl Acad Sci U S A 98:4172-4177. CrossRef Medline

Han X, Qian X, Bernstein JG, Zhou HH, Franzesi GT, Stern P, Bronson RT, Graybiel AM, Desimone R, Boyden ES (2009) Millisecond-timescale optical control of neural dynamics in the nonhuman primate brain. Neuron 62:191-198. CrossRef Medline

Ilinsky IA (1990) Structural and connectional diversity of the primate motor thalamus: experimental light and electron microscopic studies in the rhesus monkey. Stereotact Funct Neurosurg 54-55:114-124. Medline

Ilinsky IA, Kultas-Ilinsky K (1987) Sagittal cytoarchitectonic maps of the Macaca mulatta thalamus with a revised nomenclature of the motorrelated nuclei validated by observations on their connectivity. J Comp Neurol 262:331-364. CrossRef Medline

Ilinsky IA, Kultas-Ilinsky K (1990) Fine structure of the magnocellular subdivision of the ventral anterior thalamic nucleus (VAmc) of Macaca mulatta: I. Cell types and synaptology. J Comp Neurol 294:455-478. CrossRef Medline

Ilinsky IA, Yi H, Kultas-Ilinsky K (1997) Mode of termination of pallidal afferents to the thalamus: a light and electron microscopic study with anterograde tracers and immunocytochemistry in Macaca mulatta. J Comp Neurol 386:601-612. CrossRef Medline

Inase M, Buford JA, Anderson ME (1996) Changes in the control of arm position, movement, and thalamic discharge during local inactivation in the globus pallidus of the monkey. J Neurophysiol 75:1087-1104. Medline

Jones EG (2007) The thalamus. New York: Cambridge University.

Jones EG, Powell TP (1969) An electron microscopic study of the mode of termination of cortico-thalamic fibres within the sensory relay nuclei of the thalamus. Proc R Soc Lond B Biol Sci 172:173-185. CrossRef Medline

Jurgens CW, Bell KA, McQuiston AR, Guido W (2012) Optogenetic stimulation of the corticothalamic pathway affects relay cells and GABAergic neurons differently in the mouse visual thalamus. PLoS One 7:e45717. CrossRef Medline

Kakei S, Na J, Shinoda Y (2001) Thalamic terminal morphology and distribution of single corticothalamic axons originating from layers 5 and 6 of the cat motor cortex. J Comp Neurol 437:170-185. CrossRef Medline

Kliem MA, Wichmann T (2004) A method to record changes in local neuronal discharge in response to infusion of small drug quantities in awake monkeys. J Neurosci Methods 138:45-49. CrossRef Medline

Kultas-Ilinsky K, Ilinsky IA (1991) Fine structure of the ventral lateral nucleus (VL) of the Macaca mulatta thalamus: cell types and synaptology. J Comp Neurol 314:319-349. CrossRef Medline
Kuramoto E, Fujiyama F, Nakamura KC, Tanaka Y, Hioki H, Kaneko T (2011) Complementary distribution of glutamatergic cerebellar and GABAergic basal ganglia afferents to the rat motor thalamic nuclei. Eur J Neurosci 33:95-109. CrossRef Medline

Kurata K (2005) Activity properties and location of neurons in the motor thalamus that project to the cortical motor areas in monkeys. J Neurophysiol 94:550-566. CrossRef Medline

Lam YW, Sherman SM (2010) Functional organization of the somatosensory cortical layer 6 feedback to the thalamus. Cereb Cortex 20:13-24. CrossRef Medline

Landisman CE, Connors BW (2007) VPM and PoM nuclei of the rat somatosensory thalamus: intrinsic neuronal properties and corticothalamic feedback. Cereb Cortex 17:2853-2865. CrossRef Medline

Lu Y, Truccolo W, Wagner FB, Vargas-Irwin CE, Ozden I, Zimmermann JB, May T, Agha NS, Wang J, Nurmikko AV (2015) Optogenetically induced spatiotemporal gamma oscillations and neuronal spiking activity in primate motor cortex. J Neurophysiol 113:3574-3587. CrossRef Medline

Mattis J, Tye KM, Ferenczi EA, Ramakrishnan C, O’Shea DJ, Prakash R, Gunaydin LA, Hyun M, Fenno LE, Gradinaru V, Yizhar O, Deisseroth K (2012) Principles for applying optogenetic tools derived from direct comparative analysis of microbial opsins. Nat Methods 9:159-172. Medline

McFarland NR, Haber SN (2002) Thalamic Relay Nuclei of the Basal Ganglia Form Both Reciprocal and Nonreciprocal Cortical Connections, Linking Multiple Frontal Cortical Areas. J Neurosci 22:8117-8132. Medline

McMillan JL, Perlman JE, Galvan A, Wichmann T, Bloomsmith MA (2014) Refining the pole-and-collar method of restraint: emphasizing the use of positive training techniques with rhesus macaques (Macaca mulatta). J Am Assoc Lab Anim Sci 53:61-68. Medline

Miyata M (2007) Distinct properties of corticothalamic and primary sensory synapses to thalamic neurons. Neurosci Res 59:377-382. CrossRef Medline

Nambu A, Yoshida S, Jinnai K (1991) Movement-related activity of thalamic neurons with input from the globus pallidus and projection to the motor cortex in the monkey. Exp Brain Res 84:279-284. Medline

Nassi JJ, Avery MC, Cetin AH, Roe AW, Reynolds JH (2015) Optogenetic activation of normalization in alert macaque visual cortex. Neuron 86 : 1504-1517. CrossRef Medline

Ohayon S, Grimaldi P, Schweers N, Tsao DY (2013) Saccade modulation by optical and electrical stimulation in the macaque frontal eye field. J Neurosci 33:16684-16697. CrossRef Medline

Ozden I, Wang J, Lu Y, May T, Lee J, Goo W, O'Shea DJ, Kalanithi P, Diester I, Diagne M, Deisseroth K, Shenoy KV, Nurmikko AV (2013) A coaxial optrode as multifunction write-read probe for optogenetic studies in non-human primates. J Neurosci Methods 219:142-154. CrossRef Medline

Paxinos G, Huang XF, Toga AW (2000) The rhesus monkey brain in stereotaxic coordinates. San Diego: Academic

Percheron G, François C, Talbi B, Yelnik J, Fénelon G (1996) The primate motor thalamus. Brain Res Brain Res Rev 22:93-181. CrossRef Medline

Person AL, Perkel DJ (2005) Unitary IPSPs drive precise thalamic spiking in a circuit required for learning. Neuron 46:129-140. CrossRef Medline

Peters A, Palay S, Webster HD (1991) The fine structure of the nervous system, Ed 3. New York: OUP.

Pinault D (2004) The thalamic reticular nucleus: structure, function and concept. Brain Res Brain Res Rev 46:1-31. CrossRef Medline

Rouiller EM, Welker E (2000) A comparative analysis of the morphology of corticothalamic projections in mammals. Brain Res Bull 53:727-741. CrossRef Medline

Rouiller EM, Tanné J, Moret V, Kermadi I, Boussaoud D, Welker E (1998) Dual morphology and topography of the corticothalamic terminals originating from the primary, supplementary motor, and dorsal premotor cortical areas in macaque monkeys. J Comp Neurol 396:169-185. Medline

Rovó Z, Ulbert I, Acsády L (2012) Drivers of the primate thalamus. J Neurosci 32:17894-17908. CrossRef Medline

Sakai ST, Inase M, Tanji J (1996) Comparison of cerebellothalamic and pallidothalamic projections in the monkey (Macaca fuscata): a double anterograde labeling study. J Comp Neurol 368:215-228. CrossRef Medline

Sakai ST, Stepniewska I, Qi HX, Kaas JH (2000) Pallidal and cerebellar afferents to pre-supplementary motor area thalamocortical neurons in the 
owl monkey: a multiple labeling study. J Comp Neurol 417:164-180. Medline

Sherman SM (2004) Interneurons and triadic circuitry of the thalamus. Trends Neurosci 27:670-675. CrossRef Medline

Sherman SM (2005) Thalamic relays and cortical functioning. Prog Brain Res 149:107-126. CrossRef Medline

Sherman SM (2012) Thalamocortical interactions. Curr Opin Neurobiol 22:575-579. CrossRef Medline

Sherman SM, Guillery RW (2011) Distinct functions for direct and transthalamic corticocortical connections. J Neurophysiol 106:1068-1077. CrossRef Medline

Sidibé M, Bevan MD, Bolam JP, Smith Y (1997) Efferent connections of the internal globus pallidus in the squirrel monkey: I. Topography and synaptic organization of the pallidothalamic projection. J Comp Neurol 382: 323-347. Medline

Sirota MG, Swadlow HA, Beloozerova IN (2005) Three channels of corticothalamic communication during locomotion. J Neurosci 25:5915-5925. CrossRef Medline

Smith Y, Séguéla P, Parent A (1987) Distribution of GABA-immunoreactive neurons in the thalamus of the squirrel monkey (Saimiri sciureus). Neuroscience 22:579-591. CrossRef Medline
Steriade M (2001) The GABAergic reticular nucleus: a preferential target of corticothalamic projections. Proc Natl Acad Sci U S A 98:3625-3627. CrossRef Medline

Strick PL (1976) Activity of ventrolateral thalamic neurons during arm movement. J Neurophysiol 39:1032-1044. Medline

Turner RS, DeLong MR (2000) Corticostriatal activity in primary motor cortex of the macaque. J Neurosci 20:7096-7108. Medline

van Donkelaar P, Stein JF, Passingham RE, Miall RC (2000) Temporary inactivation in the primate motor thalamus during visually triggered and internally generated limb movements. J Neurophysiol 83:2780-2790. Medline

Vigneswaran G, Kraskov A, Lemon RN (2011) Large identified pyramidal cells in macaque motor and premotor cortex exhibit "thin spikes": implications for cell type classification. J Neurosci 31:14235-14242. CrossRef Medline

Vitek JL, Ashe J, DeLong MR, Alexander GE (1994) Physiologic properties and somatotopic organization of the primate motor thalamus. J Neurophysiol 71:1498-1513. Medline

Wichmann T, Bergman H, DeLong MR (1994) The primate subthalamic nucleus. I. Functional properties in intact animals. J Neurophysiol 72: 494-506. Medline 